DOI 10.18551/rjoas.2021-05.07

\title{
GENDER MAINSTREAMING AND PARTICIPATION IN CROP PRODUCTION AMONG CHAKMA FARM FAMILIES
}

\author{
Chakma Kakon, Ruba Umama Begum* \\ Faculty of Agriculture, Sylhet Agricultural University, Sylhet, Bangladesh \\ ${ }^{\star}$ E-mail: umamaruba909@gmail.com
}

\begin{abstract}
The main focus of this study was to compare gender participation in crop production activities among Chakma farm families. This survey based research was carried out in four villages of Rangamati district, Bangladesh. Using a simple random sampling technique, a total of 100 farm families ( 25 from each village) were selected for data collection. Data were collected through face to face interviews by using questionnaires. The majority of Chakma farm families were observed to undertake most of the crop production activities jointly. This study found male participation was higher than female in land preparation, water management, pest management, fertilizer management, harvesting and selling. On the other side, female participation was higher than male in planting, storing and revenue management. Overall, male participation in crop production was higher than female. It can be concluded that, though most of the crop production activities performed jointly in Chakma farming families but comparatively male had higher participation, and performed more tasks independently than female.
\end{abstract}

\section{KEY WORDS}

Indigenous, indigenous women, gender, gender role, hill tracts.

Gender mainstreaming is a strategy for reducing gender inequalities by ensuring that gender viewpoints and commitment to the target of gender inclusion (SPFII, 2007). Indigenous men and women used to have equal rights in ancient times, and indigenous men revered indigenous women, but this has deteriorated in most cases in the current world, resulting in a gap in the human development index and empowerment (SPFII, 2007). In patriarchal power structures, indigenous people face a wide range of mutually reinforcing human rights violations (Maharjan \& Thapa, 2021). Indigenous women are bound to face discrimination, vulnerable situation as they have lack of access in social benefits and decision making power, economic empowerment, education and medical facilities (Roy et al., 2015). Gender research is a tool to define and answer gender-differentiated needs in a more accurate and tailored way from a socioeconomic and poverty education viewpoint (SPFII, 2007). Thus, Indigenous women can strengthen and expand their social and economic condition by taking control on institutions, finances, and growth initiatives (SPFII, 2007).

The Chakma people live in the Chittagong Hill Tracts (CHT) region on Bangladesh's southern eastern part. Bangladesh's Chittagong Hill Tracts (CHT) is a bio-cultural diversity hotspot due to its natural resources and cultural diversity (Halim, 2007). Chakma peoples' rituals, history, and way of life are all centered on nature wealth. In all aspects of sustainable growth and development, Chakma indigenous group has a distinct knowledge network and belief system that is extremely beneficial to achieving Sustainable Development Goals (Gope et al., 2020). For food security and livelihood assistance, the Chakma population in Bangladesh's CHT is heavily reliant on forests (Miah et al., 2012). Chakma people are traditionally connected with agriculture, as Jhum cultivation is their main occupation for their livelihood. In Bangladesh's CHT, shifting production activities contributed the most revenue, whereas income from forest commodities came in second, accounting for 32 percent of household income (Miah et al., 2012). After all many changes in their lifestyle have occurred as a consequences of the loss of forested hills, climatic transition, decrease in yield and growing population. Now days shifting cultivation is becoming less common, and permanent agricultural farms are becoming more well-known. Since agricultural practices are gendered 
occupations, both men and women participate actively. Chakma women are substantially supporting the family as well as enhancing economic growth and development by their active participation and contribution. The main status of Chakma farm women roles regarded as homestead gardener, good decision maker, no interference in participation in social and family functions (Chakma et al., 2020). Chakma et al. (2020) reported that most of the Chakma farm women were uneducated, landless, showed very low cosmopoliteness, and had no modern agricultural knowledge. Bhattacharjee et al.(2020) observed the major part of Chakma farm women are far behind terms of different growth indicators. To explore current state of gender gap in Chakma farming community this study aims to compare participation of male and female in crop production activities which have significance for achieving SDGs.

\section{METHODS OF RESEARCH}

This survey based study conducted in two upazilas (Rangamati Sadar and Baghaichari) of rangamati district, Bangladesh. Within two upazila, Chakma population dominant villages namely Sapchari maddhya para, Kutukchari bazar alaka, Khedarmara and Shijakmukh were purposefully selected as the locale of this study. Household information was collected from the Union Parishad offices. A total 100 Chakma farm families (25 from each village) were selected for data collection by using simple random sampling method. Data were collected from one respondent of each family through face to face interview with the help of a modified pre tested questionnaire. To explore pattern and participation extent of gender, three forms has been used for each activity which were i) Independently performed by male, ii) Independently performed by female and iii) jointly performed. After data collection all the data were compiled, tabulated and analyzed based on objective of this study. Social characters of respondents were categorized and analyzed by using descriptive statistics such as frequency count, and percentage. For each activity, Participation Index were calculated by following way:

$$
\begin{aligned}
\text { Male PI } & =\frac{(f) \text { independently performed by male }+(f) \text { performed jointly } / 2}{\text { Total sample farm family }} \\
\text { Female PI } & =\frac{(f) \text { independently performed by female }+(f) \text { performed jointly } / 2}{\text { Total sample farm family }}
\end{aligned}
$$

\section{RESULTS AND DISCUSSION}

Socio-demographic features were categorized based on social manner and nature of data. Age group of the family heads categorized into three groups, i) young (below 30 years) ii) Middle age (30-50 years) and ii) Old (above 50 years). It was found major part of the Chakma farm family head were middle age $(70 \%)$ followed by old $(25 \%)$ and young $(5 \%)$. Though majority of them had no formal education (39\%) as they live in remote places but they possessed indigenous knowledge. Education is a fundamental human right that improves general situations, particularly social and economic conditions, and empowers people. Around $31 \%$ belonged to primary level (up to class 5 ) followed by $24 \%$ secondary level (6-10 class) and 6\% tertiary level (above class 10). Chakma families head are very much socially involved, with majority of them having socio-organizational experience $(94 \%)$ and training experience (58\%). Farm size was categorized into 4 groups, i) marginal (below $0.20 \mathrm{ha}$ ), ii) small (0.20-1 ha), iii) medium (1.01-3 ha) and iv) large (above $3 \mathrm{ha}$ ). Most of them belonged to small farm group (83\%) followed by medium $(15 \%)$ and marginal $(2 \%)$. Annual farm income was categorized into three groups, i) low (70000 TK), ii) medium (70000 to 120000 TK) and high (above 120000 TK). Majority of them belonged to low income group $(52 \%)$ led by medium (33\%) and high (15\%). People are trying to better their circumstances through their active participation in crop production activities but inadequate farm facilities render to have decrease annual farm income. Bhattacharjee et al. (2018) found in their study 
that, the majority of Chakma respondents were middle aged, illiterate, had insufficient annual family income and small size farm.

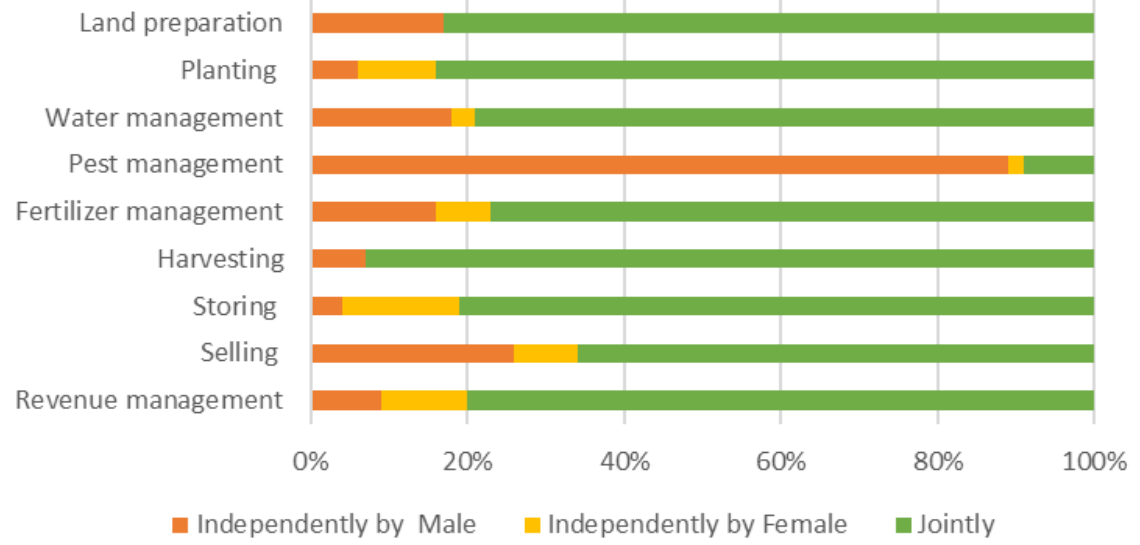

Figure 1 - Pattern of gender participation in crop production

Pattern of gender participation in crop production were measured based on their participation in various activities of crop production such as land Preparation, planting, water management, pest management, fertilizer management, harvesting, storing, selling and revenue management. Pattern of participation in each task measured by three forms; each task performed (i) independently by male, (ii) performed independently by female and (iii) performed task jointly. Figure 1 shows that Chakma farming families conducted most of their tasks jointly. It was found majority of families performed task jointly in land preparation $(83 \%)$, planting $(84 \%)$, water management $(79 \%)$, fertilizer management $(77 \%)$, harvesting $(93 \%)$, Storing $(81 \%)$, selling $(66 \%)$ and revenue management $(80 \%)$. But pest management task independently performed by male in majority of farm families $(89 \%)$.

Table 1 - Participation extent in various crop production activities

\begin{tabular}{|c|c|c|c|c|c|}
\hline \multirow{2}{*}{ Crop production Activities $(n=100)$} & Male & Female & Jointly & \multirow{2}{*}{ Male PI } & \multirow{2}{*}{ Female PI } \\
\hline & $f(\%)$ & $f(\%)$ & $f(\%)$ & & \\
\hline Land preparation & $17(17)$ & 0 & $83(83)$ & 0.585 & 0.415 \\
\hline Planting & $6(6)$ & $10(10)$ & $84(84)$ & 0.48 & 0.52 \\
\hline Water management & $18(18)$ & $3(3)$ & $79(79)$ & 0.575 & 0.425 \\
\hline Pest management & $89(89)$ & $2(2)$ & $9(9)$ & 0.935 & 0.065 \\
\hline Fertilizer management & $16(16)$ & $7(7)$ & $77(77)$ & 0.545 & 0.455 \\
\hline Harvesting & $7(7)$ & 0 & $93(93)$ & 0.535 & 0.465 \\
\hline Storing & $4(4)$ & $15(15)$ & $81(81)$ & 0.445 & 0.555 \\
\hline Selling & $26(26)$ & $8(8)$ & $66(66)$ & 0.59 & 0.41 \\
\hline Revenue management & $9(9)$ & $11(11)$ & $80(80)$ & 0.49 & 0.51 \\
\hline Average Participation Index & & & & 0.57 & 0.43 \\
\hline
\end{tabular}

Source: Field Survey, 2020.

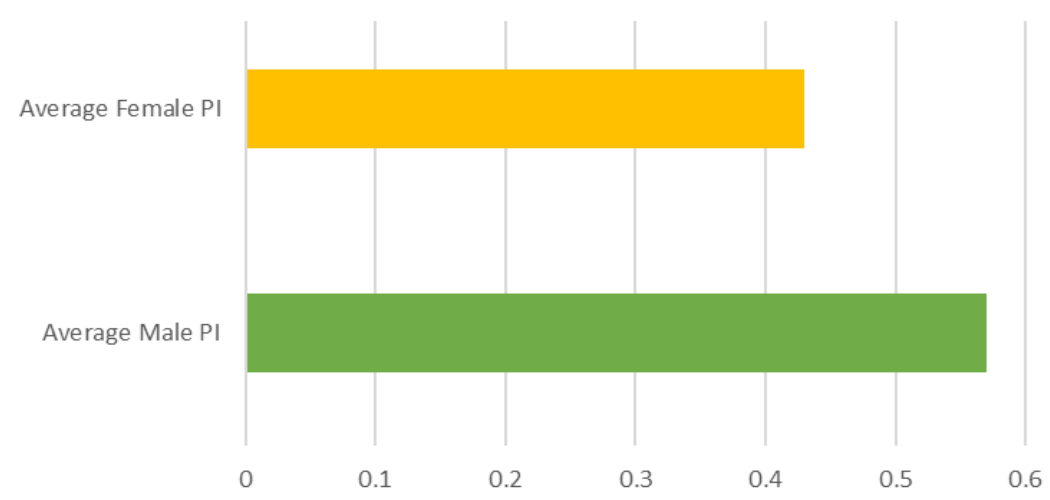

Figure 2 - Comparative Participation between Male and Female in Crop Production 
Table $1 \mathrm{It}$ was found that male participation was higher than female in land preparation (male $\mathrm{Pl}=0.585$, female $\mathrm{Pl}=0.415$ ), water management (male $\mathrm{Pl}=0.575$, female $\mathrm{Pl}=0.425$ ), pest management (male $\mathrm{Pl}=0.935$, female $\mathrm{Pl}=0.065$ ), fertilizer management (male $\mathrm{PI}=$ 0.545 , female $\mathrm{Pl}=0.455$ ), harvesting (male $\mathrm{Pl}=0.535$, female $=0.465$ ) and selling (male $\mathrm{PI}=$ 0.59 , female $\mathrm{Pl}=0.41$ ). On the other side female participation was higher than male in planting (female $\mathrm{Pl}=0.52$, male $\mathrm{Pl}=0.48$ ), storing (female $\mathrm{Pl}=0.555$, male $\mathrm{Pl}=0.445$ ) and revenue management (female $\mathrm{Pl}=0.51$, male $\mathrm{Pl}=0.49$ ). Similarly, $\mathrm{S}$. Thapa et al. (2020) also found that land holding, land preparation seed bed preparation, seed sowing, irrigation, fertilizer application and threshing are mostly performed by male than in comparison to female. Males participation was maximum in pest management activities, while female participation maximum in storing. Since pesticide spraying poses a significant health risk, it is normally carried out by men (A. Thapa et al., 2015). Women are mostly engaged in postharvest practices (Rahman, 2000) and devote more time than men on storage activities (Jahan \& Sarker, 2015). (Fig 2) Shows that, overall male participation in crop production was higher than female (Average male $\mathrm{Pl}=0.57$, Average female $\mathrm{Pl}=0.43$ ). In Bangladesh, Chakma males participated more in decision-making and field-level execution of decisions than females (Dipanwita Bhattacharjee et al., 2018).

\section{CONCLUSION}

The majority of Chakma farm families' living standards have not improved much yet as they had small farm with low income where majority of family heads were formally illiterate. Chakma farming families has been observed to perform most of their tasks jointly. In comparison of gender, we found that male participation was higher than female in land preparation, water management, pest management, fertilizer management, harvesting and selling. On the other side, female participation was higher than male in planting, storing and revenue management. Males were more involved in pest management activities while females were involved in storing. Overall, male participation in crop production was higher than female. Hence, we concluded that, though most of the activities performed jointly in Chakma farm families but comparatively male had higher participation, and performed more task independently than female.

\section{REFERENCES}

1. Bhattacharjee, D., Barau, A. A., Haque, M., \& Afrad, M. S. I. (2020). Knowledge of Chakma Women on Shifting Cultivation: A Comparative Study between Bangladesh and India. Asian Journal of Agricultural Extension, Economics \& Sociology, 57-66. https://doi.org/10.9734/ajaees/2020/v38i330324

2. Bhattacharjee, Dipanwita, Afrad, M. S. I., Haque, M. E., \& Barau, A. A. (2018). Gender mainstreaming and participation in shifting cultivation among'Chakma'tribe: A comparative study in selected areas of Bangladesh and India. Rural Extension and Innovation Systems Journal, 14(1), 11-18.

3. Chakma, A., Islam, M. S., Mitu, A. S., Rashed, M. R. U., \& Haque, M. Z. (2020). Knowledge of Chakma farm women in homestead gardening in the selected villages of Rangamati, Bangladesh. International Journal of Business, Management and Social Research, 10(01), 536-544. https://doi.org/10.18801/ijbmsr.100120.56

4. Gope, L., Behera, S. K., \& Roy, R. (2020). Identification of the Indigenous Knowledge for Sustainable Development practiced by the Chakma Community in North-East India.

5. Halim, S. (2007). Bangladesh: The interface of customary and state laws in the Chittagong Hill Tracts. Bridging the Gap: Policies and Practices on Indigenous Peoples' Natural Resource Management in Asia, 41-110.

6. Jahan, M., \& Sarker, J. R. (2015). Gender participation on rice post-harvest activities in Bangladesh. Journal of Environmental Science and Natural Resources, 8(1), 45-50. 
7. Maharjan, S. K., \& Thapa, K. (2021). Sustainable Development Goals and Indigeneity: A Practical Guide for Indigenous Peoples (Version II). Asia Indigenous Peoples Pact (AIPP).

8. Miah, D., Chakma, S., Koike, M., \& Muhammed, N. (2012). Contribution of forests to the livelihood of the Chakma community in the Chittagong Hill Tracts of Bangladesh. Journal of Forest Research, 17(6), 449-457. DOI 10.1007/s10310-011-0317-y.

9. Rahman, S. (2000). Women's employment in Bangladesh agriculture: Composition, determinants and scope. Journal of Rural Studies, 16(4), 497-507.

10. Roy, P., Tripura, F., Ghagra, S., Khyang, S., Soren, M., Chakma, C., Chakma, S., Chakma, J., Chakma, A., \& Chakma, S. (2015). Annual Situation Report 2015 on Indigenous Women in Bangladesh.

11. SPFII. (2007). Gender and Indigenous Peoples [Briefing Note]. Division of Social Policy and Development, Secretariat of the Permanent Forum of Indigenous People (SPFI) in collaboration with the office of the Special Adviser on Gender Issues and Advancement of Women- Department of Economic and Social Affairs. https://www.un.org/esa/socdev/unpfii/documents/Briefing\%20Notes\%20Gender\%20and \%20Indigenous\%20Women.pdf

12. Thapa, A., Tamrakar, A. S., \& Subedi, I. P. (2015). Pesticide Use Practices Among Tomato Growers in Kavre District, Nepal. Nepalese Journal of Zoology, 3(1), 17-23.

13. Thapa, S., Bharati, S., Jamkatel, D., \& bam, shubham. (2020). Survey on gender role in rice production by farmers of Nuwakot district, Nepal. Archives of Agriculture and Environmental Science, 5. https://doi.org/10.26832/24566632.2020.0502012 